\title{
Cisto hidático intramuscular: relato de caso
}

\author{
Intramuscular hydatid cyst: a case report \\ Marcus Klay Silveira Chiattoni ${ }^{1}$, Valéria Jorge ${ }^{2}$, Heitor Alberto Jannke ${ }^{2}$, \\ Guilherme Heiden Teló ${ }^{3}$ e Nelissa Cristina Correa Segala ${ }^{3}$
}

\begin{abstract}
Resumo A localização muscular dos cistos hidáticos é incomum $(0,5$ a 5,4\%) e geralmente secundária à doença hepática ou pulmonar. Reporta-se um caso de hidatidose intramuscular glútea, chamando-se a atenção para essa localização atípica da doença, que deve ser considerada na prática cirúrgica. A inexistência de cistos concomitantes nas sedes mais comuns confere interesse ainda maior ao caso apresentado.
\end{abstract}

Palavras-chaves: Cisto hidático. Músculo. Região glútea. Anatomia patológica.

Abstract The muscular localization of the hydatid cyst is uncommon (0.5 to $5.4 \%$ ) and it is usually secondary to hepatic or pulmonary disease. A case of gluteus intramuscular hydatid cyst is reported, calling attention to this atypical localization of the disease, which should be taken into account in the practice of surgery. The absence of residual cysts in the most common sites confers a higher interest to the case reported in this work. Key-words: Hydatid cyst. Muscle. Gluteus region. Anatomical pathology.

A hidatidose é uma antropozoonose endêmica na América do Sul, Austrália e países do Mediterrâneo, causada pela forma larvária de cestódios do gênero Echinococcus, usualmente E. granulosus ${ }^{1311}$.

Os seres humanos podem contrair a infecção pelo contato direto com cães (hospedeiro definitivo), ou pela ingestão de alimentos contaminados com ovos de E. granulosus, presentes nas fezes desses animais. Depois de ingeridos, os ovos se rompem e as larvas penetram na mucosa do intestino delgado, atingindo os canais linfáticos e venosos ${ }^{91013}$.

Os sítios mais freqüentemente atingidos são o fígado e os pulmões ${ }^{3}{ }^{12}$. A localização muscular do cisto hidático é incomum, mesmo em países onde a endemicidade é alta, ocorrendo em cerca de 0,5 a $5,4 \%$ dos $\operatorname{casos}^{811}$.

Os cistos hidáticos intramusculares apresentam crescimento lento e geralmente são assintomáticos, manifestando-se basicamente pela presença de massa palpável ${ }^{14810}$.

O presente relato tem por objetivo apresentar um caso de hidatidose intramuscular, discutindo suas peculiaridades, expondo os achados anatomopatológicos e chamando a atenção para seu diagnóstico na prática cirúrgica.

\section{RELATO DO CASO}

Mulher branca de 71 anos de idade, natural e procedente de Herval do Sul (RS), foi hospitalizada na Santa Casa de Misericórdia de Pelotas (RS) para realização de cirurgia de revascularização miocárdica. No exame clinico pré-operatório, verificou-se tumefação palpável, indolor, de aspecto cístico e que drenava líquido, na região glútea esquerda. Foram realizadas drenagem e análise microbiológica; esta não evidenciou crescimento bacteriano. $O$ estudo ultrassonográfico da região revelou a presença de grande formação cística, sugestiva de cisto hidático.

Os exames laboratoriais solicitados (hemograma, glicemia de jejum, uréia, creatinina, sódio, potássio, tempo de protrombina e tempo de coagulação) revelaram-se dentro da normalidade. Os estudos ultrassonográfico do fígado e radiológico do pulmão não evidenciaram particularidades dignas de nota, principalmente no que diz respeito à presença de cistos hidáticos.

\footnotetext{
1. Departamento de Cirurgia da Santa Casa de Misericórdia de Pelotas, Pelotas, RS. 2. Disciplina de Patologia da Escola de Medicina da Universidade Católica de Pelotas, Pelotas, RS. 3. Escola de Medicina da Universidade Católica de Pelotas, Pelotas, RS.

Endereço para correspondência: Dr. Heitor Alberto Jannke. R. Orlando B. de Azevedo 318, Colina do Sol, $96020-540$ Pelotas, RS.

Tel: 53 283-6511.

e-mail:jannke@terra.com.br

Recebido para publicação em 23/5/2002

Aceito em 6/6/2003
} 
Com o diagnóstico de tumor cístico na região glútea, indicou-se tratamento cirúrgico. No transoperatório, verificou-se cisto circunscrito por membrana fibrótica e com presença de membranas brancas no seu interior, acometendo o músculo glúteo máximo esquerdo. A lesão foi extirpada em monobloco, sendo o produto encaminhado para estudo anatomopatológico.

A análise macroscópica mostrou formação ovóide, grosseiramente granulosa, medindo cerca de $6 \mathrm{~cm}$ no maior eixo. Foi recebida aberta, mostrando membrana anista leitosa característica de cistos hidáticos (Figura 1), cercada por grossa carapaça fibrótica (pericística). Os cortes microscópicos foram corados por hematoxilina-eosina, Van Giesen e tricrômico de Azam e mostraram estrutura lamelar típica de membrana anista (Figura 2), fibrose e tecido muscular esquelético adjacente. Firmou-se assim o diagnóstico de cisto hidático intramuscular.

A paciente apresentou evolução bastante favorável, sem qualquer intercorrência.

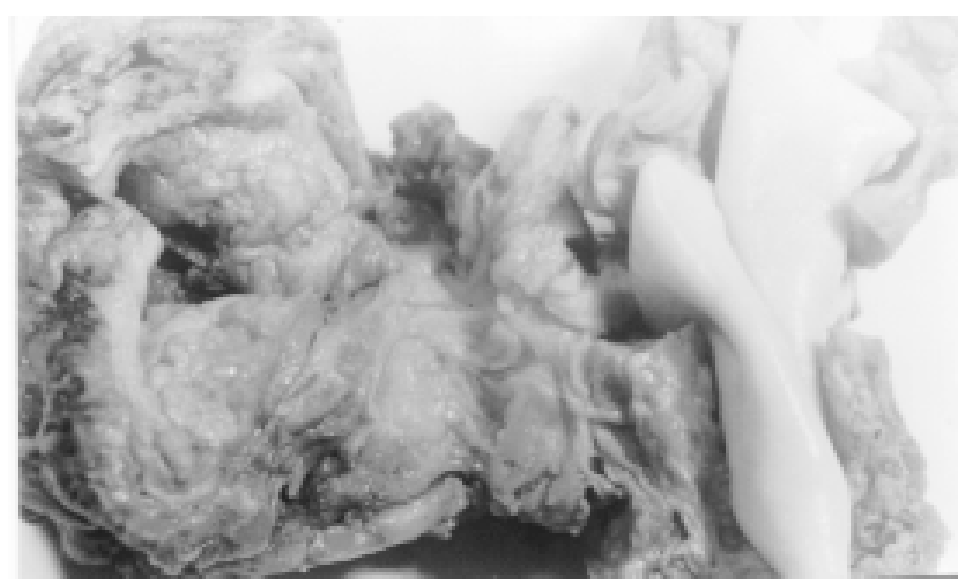

Figura 1 - Aspecto macroscópico do cisto hidático, em que se visualizam membrana anista característica (à direita) e tecido muscular adjacente.

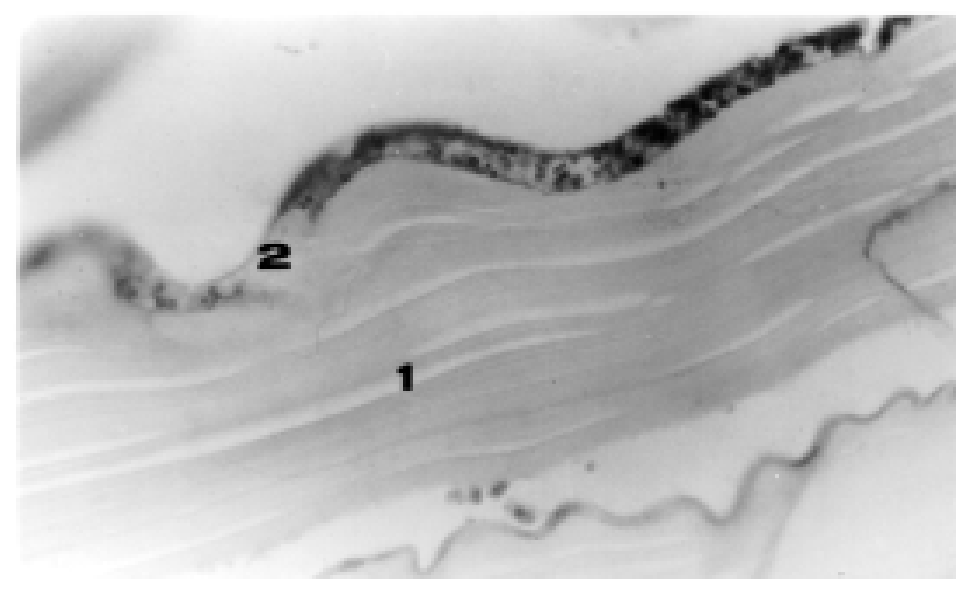

Figura 2 - Microscopia corada por tricrômico de Azam, mostrando: 1. membrana anista e 2. membrana prolígera/germinativa (100x).

\section{DISCUSSÃO}

Trata-se de um caso de hidatidose intramuscular na região glútea esquerda, confirmada cirúrgica e anatomopatologicamente. A suspeita diagnóstica foi levantada tendo-se em vista a procedência rural e endêmica da paciente, o freqüente contato com cães e o crescimento lento e assintomático da tumoração, que se apresentava de forma cística.

A hidatidose é uma doença de ocorrência predominantemente rural, em função da maior exposição dessa população aos agentes transmissores 
da doença, levando-se em conta o ciclo evolutivo do Echinococcus granulosus 58 .

O quadro clínico não é específico. A evolução é lenta e, na maioria das vezes, assintomática. Os cistos apresentam-se como tumefações indolores, sem sinais inflamatórios e aderidos a planos profundos, que aumentam progressivamente de tamanho. As manifestações clínicas são geralmente causadas pela compressão do cisto sobre o órgão envolvido ou sobre estruturas vizinhas ${ }^{13} 10$.

A raridade dos cistos hidáticos intramusculares, previamente referida ${ }^{811}$, pode ser explicada pela dificuldade do embrião hexacanto ultrapassar as barreiras hepática e pulmonar, pela contratilidade muscular e pela intensa produção de ácido láctico, que impedem o desenvolvimento do parasita dentro do músculo ${ }^{3811}$.

Quanto à via de acesso do parasita ao tecido muscular, a mais aceita é a arterial. O embrião, após transpor a barreira hepatopulmonar, é veiculado à circulação geral, podendo ser levado a qualquer região do corpo, onde se transforma em cisto plenamente desenvolvido 61011

Os cistos hidáticos intramusculares podem ser primários ou secundários à doença pulmonar e hepática. A hidatidose muscular, na ausência de outra localização, é pouco conhecida ${ }^{1011}$. Por isso, faz-se muito importante a realização de métodos diagnósticos por imagem para a exclusão da enfermidade nos sítios mais freqüentes ${ }^{12}$. No caso apresentado, os estudos ultrassonográfico do fígado e radiológico do pulmão apresentaram-se sem particularidades, o que confere raridade ainda maior ao presente relato.

Como diagnósticos diferenciais da hidatidose muscular podem-se considerar, entre outros, os tumores benignos e malignos de partes moles, os abscessos e os cistos sinoviais e hemáticos ${ }^{13510}$.

No diagnóstico pré-operatório, pode-se utilizar o raio$X$ simples, exame capaz de evidenciar calcificações no caso de cistos antigos. O ultrassom também é útil, identificando a natureza hidática das lesões em aproximadamente $95 \%$ dos casos. A tomografia computadorizada e a ressonância magnética, apesar de serem métodos de alta qualidade, geralmente só vêm a ser solicitadas em situações de incerteza diagnóstica ${ }^{2413}$.

A cirurgia tem sido utilizada tanto como método diagnóstico, quanto terapêutico. A ausência de doenças associadas no fígado e pulmões, bem como a natureza unilocular da tumoração são de extrema importância, pois o tratamento cirúrgico passa a ser ainda mais indicado $^{912}$. A incisão deve envolver todo o material parasitário, tendo-se cuidado para evitar a iatrogenia (disseminação e choque anafilático). Na maioria dos casos, a evolução dos pacientes transcorre sem complicações ${ }^{811}$.

\section{REFERÊNCIAS BIBLIOGRÁFICAS}

1. Angulo JC, Granell J, Muguerza J, Sanchez-Chapado M. Primary bilateral hydatidosis of the psoas muscle. The Journal of Urology 161:1557-1558, 1999

2. Bayram M, Sirikci A. Hydatid cyst located intermuscular area of the forearm: MR imaging findings. European Journal of Radiology $36: 130-132,2000$

3. Benchekroun A, Jira H, Cheikhani OJ, Kasmaoui EH, Zannoud M, Faik M. Kyste hydatique du psoas. À propos d'un cas. Annales D'Urologie 35:108-110, 2001.

4. Cissé AM, Nassar I, Hammani L, Dafiri R, Imani F. Hydatidose primitive et étendue de la cuisse: aspect radiologique inhabituel. Journal de Radiologie 83:1778-1780, 2002.

5. Daali M, Hssaida R. L'hydatidose musculaire. La Presse Médicale 29:1166-1169, 2000.

6. De Vega DS, Vazquez E, Calvo E, Tamames S, Tamames S. Kyste hydatique du diaphragme: a propos d'un cas. Journal de Chirurgie 128:76-78, 1991.

7. Essadki O, Elhajjam M, Kadini R. Kystes hydatiques des parties molles: aspects radiologiques. Annales de Radiologie 39:135141,1996
8. Fikry T, Harfaoui A, Sibai H, Zryouil B. L'échinococcose musculaire primitive: a propos de deux cas. Journal de Chirurgie 134:325328, 1997.

9. Gomes NH, Renck DV, Cunha DE, Orlandini LP. Hidatidose do esterno e musculatura peitoral. Jornal de Pneumologia 27:223226, 2001

10. Gossios KJ, Kontoyiannis DS, Dascalogiannaki M, Gourtsoyiannis NC. Uncommon locations of hydatid disease: CT appearances. European Radiology 7:1303-1308, 1997.

11. Latino R, Costa S, Barbagallo E, Virzì A, Vagnoni G. Localizzazione muscolare primaria di cisti idatidea del gran dorsale: caso clinico. Annali Italiani di Chirurgia 70:123-126, 1999.

12. Merkle EM, Schulte M, Vogel J, Tomczak R, Rieber A, Kern P, Goerich J, Brambs HJ, Sokiranski R. Musculoskeletal involvement in cystic echinococcosis: report of eigth cases and review of the literature. American Journal of Roentgenology 168:1531-1534, 1997.

13. Von Sinner WN. New diagnostic signs in hydatid disease; radiography, ultrasound, CT and MRI correlated to pathology. European Journal of Radiology 12:150-159, 1991. 